\title{
MURRA Y EL PUEBLO ESPAÑOL ${ }^{1}$
}

\author{
Nicolás Sánchez-Albornoz ${ }^{2}$
}

Mi participación en un homenaje en recuerdo de John V. Murra se justifica por la admiración y la amistad que le profesé, pero no a todos los amigos que tuvo, muchos y buenos, se les ha pedido su adhesión. Tampoco pertenezco a la grey de antropólogos o de discípulos con la que él estuvo relacionado por razones profesionales. Necesito pues comenzar exponiendo motivos para el privilegio que se me ha concedido. Empezaré señalando algunas coincidencias que nos acercaron.

A John Murra y a mí nos ha unido, curiosamente, una renuncia de jóvenes a la arqueología. En mi haber cuento con lejanos artículos sobre pinturas rupestres y restos líticos superficiales hallados en la Patagonia, con la excavación de abrigos en la misma región y con la imprevista identificación de materiales neolíticos en la lejana Tierra de Fuego. Buen comienzo éste para haber seguido una carrera en esa especialidad. Sin embargo, me aparté de ella. Esa dedicación pasajera dejó sin embargo en mí un rastro al que atribuyo en parte mi determinación posterior por estudiar a los indígenas andinos históricos. Aunque más tardíos, ellos no eran menos ágrafos como sus predecesores, con la diferencia de que su traza no se rastrea en las hendiduras abiertas en la tierra, sino que se desprende de la lectura de documentos coloniales, esto es, en censos, registros y demás compilaciones.

La retirada del pasaporte a Murra, con prohibición de abandonar los Estados Unidos, le obligó a renunciar al trabajo de campo arqueológico que se disponía a hacer en los Andes. La persecución política no le impidió sin embargo ocuparse de los hombres y mujeres de la región. La renuncia forzada a la arqueología desplazó su mira hacia los andinos menos remotos y le llevó a informarse en otro género de fuentes. Para el período prehispánico, Murra leyó las crónicas coloniales con ojos de etnólogo y acabó por fundar una disciplina nueva, la etnohistoria. Nuestra común dependencia de la letra escrita espoleó que leyéramos y comentáramos lo que salía de nuestras plumas. El encuentro intelectual se vio reforzado al descubrir más afinidades.

Ambos éramos exiliados: el uno, de una Rusia imperial dejada atrás en la primera infancia, con crianza en Rumania que se convirtió en una etapa hacia los Estados Unidos; el otro, yo mismo, educado en Francia en un primer exilio, evadido de España en la adolescencia y con un alto en el camino en la Argentina y destino último también en los Estados Unidos. A los desarraigos sumábamos militancias estudiantiles y experiencias carcelarias. La memoria de la guerra civil de España fue otro punto de coincidencia.

John Murra nunca prodigó sus datos biográficos. Pocos eran los que conocían el nombre que recibió por nacimiento, el lugar en que éste se produjo (le teníamos por rumano) o el camino que le condujo hasta Chicago. No había negación u ocultación por parte suya, pero daba la impresión de que los antecedentes personales significaban poco para él. No consideraba que hubieran configurado su manera de ser, sino que ella dependía de su obrar. Los acontecimientos fundamentales sucedieron en su juventud. La Universidad de Chicago le dotó de la racionalidad intelectual y académica que se afanó por aplicar en su vida; la guerra de España le enriqueció humanamente y centró su adhesión social y política. Murra concedió prioridad a la experiencia vital sobre el aprendizaje formal. "Yo soy graduado de la guerra civil española. No de la Universidad de Chicago". Sólo en los últimos años Murra cedió ante las presiones de sus seguidores y concedió entrevistas que permiten adentrarse en su compleja individualidad. De una de esas entrevistas extraigo las palabras que acabo de citar.

En los homenajes que se le rinden, sus colegas se referirán a su aporte al mundo andino, como su reconstrucción del sistema económico y político que rigió en el Tawantisuyo, al aprovechamiento vertical de pisos ecológicos complementarios propicio a un abastecimiento diversificado de una población rural en

\footnotetext{
1 Sesión conmemorativa para JV Murra, École des Hautes Études en Science Sociale, Paris, 25 enero 2007. Acto homenaje a John V. Murra, Institut d'Estudis Catalans, Barcelona, 20 de febrero de 2007, Institut d'Estudis Catalans, Barcelona.

2 Profesor Emeritus de la New York University, New York, USA.
} 
crecimiento o al peso ritual y político que los tejidos revistieron en ese sistema. En las contribuciones respectivas, sus discípulos han de evocar sobre todo su generosidad a la hora de compartir conocimientos y la fascinación que sus exposiciones despertaban. Los amigos resaltarán sus calidez humana. No faltará pues faceta de su existencia que la desaparición del colega, del maestro y del amigo deje sin echar de menos, ¿Repeticiones? Es inevitable que se den, pero en lo que a mí respecta procuraré evitarlas al ocuparme sólo de un aspecto, si bien no ignorado, menos mencionado entre académicos y andinos. Ese rasgo es la especial relación que mantuvo con España o mejor dicho, precisión importante, con el pueblo español.

El estudiante politizado que el estallido de la guerra civil en España sorprendió en 1936 en las aulas de la Universidad de Chicago encandilado por los destellos de la antropología, ese joven tardó semanas en plantar sus estudios y alistarse, a los veinte años, en las Brigadas Internacionales que los partidos comunistas promovieron por todas partes para acudir en socorro del pueblo español agredido por fuerzas internas, apoyadas por regímenes fascistas. Juventud y conciencia política le llevaron a España, no sin que antes el grupo con el que viajaba tuviera que vencer el sinfín de trabas que se interponían en su camino. Los Estados Unidos, presididos por un Franklin D. Roosevelt, con fama hoy de progresista, hicieron lo posible para impedir que del país partieran hombres y pertrechos para el bando republicano.

En España, fue destinado a Albacete donde se adiestraba a los brigadistas para entrar en combate. Murra fue adscrito a la organización central del campamento en la que su fluido conocimiento de media docena de idiomas resultaba imprescindible para que hombres y mandos de procedencias y lenguas diversas pudieran comunicarse entre sí. El entusiasmo desplegado por los voluntarios no impedía que surgieran dificultades prácticas como ésta. En Albacete, la capacidad mostrada ganó al soldado raso autoridad en el Estado Mayor. En la entrevista publicada deja caer con ironía: "Actuaba como oficial pero cobraba como soldado".

La intimidad con los superiores militares y políticos al mando de las Brigadas Internacionales provocó en él una primera desilusión. Descubrió debilidades, incapacidades y sectarismos. Resultan patéticas sus alusiones a la conducta del dirigente estalinista francés André Marty, quien por lo visto estuvo a punto de fusilarle. La decepción le llevó a un distanciamiento del partido comunista, aunque no de los ideales que le habían llevado a España. Murra cuidó mucho en distinguir las discrepancias que mantenía con la organización de, por otro lado, la viva adhesión que mantuvo a las reivindicaciones sociales.

La segunda insatisfacción fue con el trabajo que hacía. Murra consideraba que no había dejado sus estudios y acudido a España para convertirse en un burócrata por útil que fuera la función que desempeñaba. Había venido a combatir con las armas en la mano. A Murra no se le ocurrió cosa mejor que desertar del Estado Mayor y unirse a una unidad que marchaba al frente. Aquí, cayó herido en las líneas enemigas por dos disparos en la pierna que le imposibilitaron replegarse cuando la avanzadilla lo hizo. Aquí introduzco una anécdota que no puedo olvidar por la emoción que despertó. En uno de los banquetes conmemorativos que los veteranos de la Brigada Lincoln celebraban anualmente en Nueva York por febrero, coincidí en la mesa con él. Había venido de afuera para la ocasión. De repente noté que se levantaba, se dirigía a otra mesa y se fundía en un largo abrazo con otro comensal. Después supe que hacía cuarenta años que no se veían y que aquel al que había estrechado era el compañero que fue por él y lo arrastró bajo fuego enemigo hasta la trinchera republicana. A él le debía pues la vida.

Murra fue evacuado a la retaguardia. En Barcelona fue operado y en Mataró pasó su convalecencia. La herida le dejó una ligera cojera para toda la vida, pero no le impidió caminar. La retirada de las Brigadas Internacionales, acordada por el gobierno de la República, no le incluyó. Las autoridades francesas no le aceptaban para su repatriación a los Estados Unidos. Por consiguiente tuvo que ganar Francia a pie en medio de la retirada del ejército republicano de Cataluña. Del otro lado de la frontera, le esperaban los campos de internamiento franceses, en particular el famoso de Argelès-sur-Mer. El éxodo representó pues para él un desgarro igual al que experimentaron los refugiados españoles. Murra se encontraba tan identificado con la causa republicana que él mismo confesó: "de haber vencido la República, dudo que hubiera regresado a los Estados Unidos".

Pero volver a Chicago resultaba la mejor opción disponible a mediados de 1939, cuando ya sonaban tambores de guerra en Europa. No le fue fácil obtener un visado de entrada, pero la preferencia de las 
cuotas americanas por los inmigrantes universitarios y las fianzas depositadas por profesores y amigos consiguieron vencer los inconvenientes. Los que no obtuvieron entonces ese visado, la Segunda Guerra les sorprendió en Francia y -comenta- los campos nazis los engulleron.

Murra permaneció lejos de España los años de la guerra mundial, de la persecución maccartista en los Estados Unidos y de la prolongación de la dictadura franquista tras la victoria aliada. Puso el pie en ella tarde y por razones profesionales. Acude para perseguir en el Archivo de Indias de Sevilla algún filón de sus investigaciones sobre los Andes. Su vuelta a España asidua se demora sin embargo hasta el cambio radical en las condiciones políticas y sociales que sucede a la dictadura. Entonces visita a colegas y amigos, enseña, publica, pero vuelve también para enlazar con el pasado. Recorre los escenarios en los que había estado. Consulta los documentos de archivos que le conciernen y abriga incluso la ilusión de un reconocimiento moral por su condición de combatiente y de mutilado. De la gente de una época nueva recibe sí un agradecimiento efusivo por su veteranía y por la talla intelectual que el joven soldado había conquistado desde su participación en la guerra de España. Expresión de ese doble respeto es el doctorado honoris causa que la Universidad de Barcelona le concedió. Murra escuchó complacido las sugerencias que algunos amigos también le hicimos para que se instalara en España, ya jubilado, huyendo de los fríos de Ithaca, pero nunca se decidió.

Que los sentimientos de Murra permanecieran anclados por decenios en lo que hace a España tiene poco de particular. En los demás veteranos de la Brigada Lincoln he conocido igual fidelidad a la causa que defendieron y un afecto entrañable hacia el pueblo español sufriente que conocieron. Lo especial en el caso de Murra es que ahí donde sus camaradas no tropezaban con inconveniente alguno para seguir dividiendo a los españoles en blanco y negro, al modo en que les clasificaron durante la guerra civil, él, en cambio, al remontarse al pasado, se topó con otra clase de españoles que complicaban su visión. Su experiencia de guerra no le permitía caer en la generalización fácil que suelen hacer los antropólogos y los políticos indigenistas.
No podía demonizar al conjunto de españoles, al tiempo que su nueva lealtad a los andinos interfería en la suya anterior.

El conflicto entre ambas lealtades era aparente antes que nada porque los españoles con los que Murra simpatizaba no eran los conquistadores, sino los campesinos y obreros que se levantaron contra los fascistas herederos en actitudes de éstos. Dos géneros de españoles: distintos y enfrentados. Por otro lado, los andinos que estudiaba, no fueron el linaje de los incas, la nobleza o los sacerdotes. Murra ha tratado muchos temas pero no el específico de la religión andina. Tampoco por cierto se ocupó de los hechos de la Conquista. La esfera que sus estudios recorrieron fue la social. En la entrevista que el antropólogo Rowe le hizo, Murra reconoce no haberse desprendido de un poso de su pensamiento marxista originario que le indujo a preocuparse por ciertas facetas del pasado andino y no por otras. Se afanó por comprender los mecanismos por los cuales una comunidad campesina consiguió reproducirse $\mathrm{y}$ crecer al acecho de unas condiciones tan precarias como las que se dan en las alturas andinas. Interés impregnado de admiración. Al cruzar de un continente a otro, el grupo social con el que se sentía concernido no varió. Los afectos no resultaron por consiguiente imposibles de compaginar.

Quedaban sin embargo flecos por resolver fuera de su ánimo. Se ha observado más de una vez que al referirse al conflicto que opuso a andinos y conquistadores, Murra llama a éstos rara vez españoles, sino europeos. Con la distinción, entiende restar carácter étnico al enfrentamiento y conducirlo a una confrontación más amplia entre sistemas sociales y económicos a escala mundial, en la cual los españoles desempeñaron un papel instrumental. Dentro de esta perspectiva, Murra fue también capaz de ocuparse con cierta simpatía de personajes del mundo colonial, tales como Polo de Ondegardo o Domingo de Santo Tomás, por descubrir en ellos, pese al lugar que ocupaban en la sociedad colonial, un respeto por las concepciones y los comportamientos de la gente andina.

John V. Murra persiguió una aventura intelectual no exenta de sentimientos. Como queda apuntado, su participación en la guerra de España le proporcionó un buen caudal de emociones. 
